\title{
Vitamin D supplementation as an adjuvant therapy for patients with T2DM: an 18-month prospective interventional study
}

Nasser M Al-Daghri ${ }^{1,2,3^{*}}$, Khalid M Alkharfy ${ }^{1,2,4}$, Abdulaziz Al-Othman ${ }^{5}$, Emad El-Kholie ${ }^{1}$, Osama Moharram ${ }^{6}$ Majed S Alokail ${ }^{1,2,3}$, Yousef Al-Saleh ${ }^{3,7}$, Shaun Sabico ${ }^{1,3}$, Sudhesh Kumar ${ }^{8}$ and George P Chrousos ${ }^{1,9}$

\begin{abstract}
Background: Vitamin D deficiency has been associated with impaired human insulin action, suggesting a role in the pathogenesis of diabetes mellitus type 2 (T2DM). In this prospective interventional study we investigated the effects of vitamin D3 supplementation on the metabolic profiles of Saudi T2DM subjects pre- and post-vitamin D supplementation over an 18-month period.

Methods: T2DM Saudi subjects (men, $N=34$ : Age: $56.6 \pm 8.7 \mathrm{yr}, \mathrm{BMl}, 29.1 \pm 3.3 \mathrm{~kg} / \mathrm{m}^{2}$; women, $\mathrm{N}=58$ : Age: $51.2 \pm 10.6 \mathrm{yr}$, BMI $34.3 \pm 4.9 \mathrm{~kg} / \mathrm{m}^{2}$;) were recruited and given $2000 \mathrm{IU}$ vitamin D3 daily for 18 months.

Anthropometrics and fasting blood were collected $(0,6,12,18$ months) to monitor serum 25-hydroxyvitamin $D$ using specific ELISA, and to determine metabolic profiles by standard methods.

Results: In all subjects there was a significant increase in mean 25 -hydroxyvitamin $D$ levels from baseline $(32.2 \pm 1.5 \mathrm{nmol} / \mathrm{L})$ to 18 months $(54.7 \pm 1.5 \mathrm{nmol} / \mathrm{L} ; p<0.001)$, as well as serum calcium (baseline $=2.3 \pm 0.23 \mathrm{mmol} / \mathrm{L}$ vs. 18 months $=2.6 \pm 0.1 \mathrm{mmol} / \mathrm{L} ; p=0.003$ ). A significant decrease in $L D L$ - (baseline $=4.4 \pm 0.8 \mathrm{mmol} / \mathrm{L} \mathrm{vs}$. 18 months $=3.6 \pm 0.8 \mathrm{mmol} / \mathrm{L}, p<0.001$ ] and total cholesterol (baseline $=5.4 \pm 0.2 \mathrm{mmol} / \mathrm{L}$ vs. 18 months $=4.9 \pm 0.3 \mathrm{mmol} / \mathrm{L}, p<0.001$ ) were noted, as well as a significant improvement in HOMA- $\beta$ function $(p=0.002)$. Majority of the improvements elicited were more prominent in women than men.

Conclusion: In the Saudi T2DM population receiving oral Vitamin D3 supplementation (2000 IU/day), circulating 25-hydroxyvitamin D levels remained below normal 18 months after the onset of treatment. Yet, this "suboptimal" supplementation significantly improved lipid profile with a favorable change in HDL/LDL ratio, and HOMA- $\beta$ function, which were more pronounced in T2DM females.
\end{abstract}

Keywords: Vitamin D, Diabetes mellitus, Saudi, Supplementation

\section{Background}

In recent years, vitamin D deficiency has gained unprecedented attention in the fields of preventive cardiology and endocrinology, primarily because of the extraskeletal pleiotropic effects of this hormone, and the association of its deficit with insulin resistance, diabetes mellitus and an increased cardiovascular risk [1-3]. A unifying factor that links diabetes mellitus types 1 and

\footnotetext{
* Correspondence: aldaghri2011@gmail.com

'Biomarkers Research Program, Biochemistry Department, College of Science, King Saud University, PO Box, 2455, Riyadh 11451, Kingdom of Saudi Arabia ${ }^{2}$ Center of Excellence in Biotechnology Research Center, King Saud University, Riyadh 11451, Kingdom of Saudi Arabia

Full list of author information is available at the end of the article
}

2 (T1DM and T2DM, respectively) is the expression of vitamin $\mathrm{D}$ receptors (VDRs) in more than 30 biological tissues, including the pancreatic islet cells [3-5]. On the other hand, it is common for patients with T1DM and T2DM to have vitamin D deficiency [6]. Furthermore, several longitudinal and observational studies have demonstrated that low levels of serum 25hydroxyvitamin D predict T2DM risk in Europeans [7,8], African-Americans [9], South Asians [10] and native American children [11]. Vitamin D correction, therefore, may increase insulin secretion and improve glucose homeostasis; however, its effects on healthy individuals or in those with impaired glucose tolerance remain unclear [6]. 
In the Middle East and North Africa (MENA), vitamin D deficiency is startlingly high as compared to other geographical regions [12]. Specifically, in the kingdom of Saudi Arabia (KSA), where the intensity of sunlight is paradoxically directly proportional to the prevalence of vitamin D deficiency [13], hypovitaminosis $\mathrm{D}$ has been implicated not only as a significant predictor of osteoporosis among apparently healthy men and post-menopausal women $[14,15]$, but also significantly associated to cardiometabolic risk factors in both children and adults [16,17]. Interestingly, there is an equally alarming prevalence of chronic non-communicable diseases in KSA, including T2DM, obesity, the metabolic syndrome, and cardiovascular diseases [18].

Previously we demonstrated a modest reversal of metabolic syndrome manifestations among a cohort of adult Saudis who were advised vitamin D correction through increased sun exposure and dietary vitamin $\mathrm{D}$ intake [19]. In the current interventional study, we aimed to determine the metabolic effects of oral vitamin D supplementation in a cohort of T2DM Saudi subjects over time. This study may shed light as to whether oral vitamin D supplementation can be an adjunct therapy in T2DM Saudi patients, and on the importance of optimizing vitamin $D$ levels in the prevention and improved management of chronic non-communicable diseases such as T2DM.

\section{Methods}

\section{Site and duration of the study}

This is a multi-center, interventional study conducted at the primary health care out -patient clinics in Riyadh, Kingdom of Saudi Arabia. Ethics approval was obtained from the ethics committee of the College of Medicine Research Center at King Saud University, Riyadh, KSA.

\section{Subjects}

A total of 120 adult Saudi patients (males and females) with controlled T2DM (known cases), aged 30 year and above but not exceeding 70 years, were randomly recruited for the study. Subjects were excluded if taking mineral oil products, using antacids regularly, taking cortisone or other steroids, diuretics, weight-loss drugs, phenobarbital and phenytoin, having liver problems, gallbladder disease or gastrointestinal disorders and taking daily multivitamins. Patients receiving hypoglycemic agents and statins were allowed in the study and changes in drug doses were noted.

All subjects were given a general questionnaire, which includes thorough past and present medical history. They then underwent a physical examination and required to submit written informed consents prior to being included in the study. All subjects were given a six-month supply of 2000 IU Vitamin D3 tablets
(Vigantoletten; Merck Pharma, Germany) to be taken daily, after which and every 6 months they were to return to their assigned primary care center for another examination and prescription refill.

\section{Anthropometry}

All anthropometric parameters were obtained while the subject was standing erect and barefoot. Height and weight were determined using standardized conventional methods. Body mass index (BMI) was calculated using the formula: weight in kilograms $(\mathrm{kg})$ divided by height in squared meters $\left(\mathrm{m}^{2}\right)$. A standardized mercurial sphygmomanometer was used to take the blood pressure of each participant 30 min after complete rest.

\section{Laboratory parameters}

Fasting blood samples were collected at baseline for quantification of different metabolic parameters. This procedure was repeated every 6 months prior to the refill of the next vitamin D supplements. Fasting blood glucose, lipid profile, albumin, phosphorous and calcium were determined using routine laboratory procedures (Konelab, Espoo, Finland). Serum insulin was quantified using multiplex assay kits (Lumine ${ }^{\circledR}$ xMAP $^{\circledR}$ Technology platform) (Luminexcorp, Texas). The intra-assay variation was $1.4-7.9 \%$ and inter-assay variation of $<21 \%$. Minimum detectable concentration (MDC) for insulin was $50.9 \mathrm{pg} / \mathrm{ml}$. Parathyroid hormone (PTH) and 25-hydroxy-vitamin D were measured using enzymelinked immunosorbent assay (IDS Ltd., Boldon Colliery, Tyne \& Wear, UK). The inter- and intra-assay variabilities were $5.8 \%$ and $3.4 \%$, for intact PTH, and $5.3 \%$ and $4.6 \%$, for 25 -hydroxyvitamin $\mathrm{D}$, respectively. All measurements were performed in a DEQA- (Vitamin D External Quality Assessment) participating laboratory, the Biomarkers Research Program (BRP) of King Saud University, Riyadh, KSA.

Homeostasis model assessment for insulin resistance (HOMA-IR) was calculated as fasting insulin (IU) $\mathrm{x}$ fasting glucose $(\mathrm{mmol} / \mathrm{L}) / 22.5$. HOMA- $\beta$ secretion (\%) was calculated as $20 \mathrm{x}$ fasting insulin (IU)/(fasting glucose3.5) [20]. Vitamin D deficiency was defined as serum 25hydroxyvitamin D level $<50 \mathrm{nmol} / \mathrm{L}$.

\section{Statistical analysis}

The Statistical Package for the Social Sciences (SSPS) for Windows version 16.5 (Chicago, Illinois) was used for statistical evaluation of data. Variables exhibiting nonGaussian distribution were logarithmically transformed. Repeated measures analysis of variance (ANOVA) was undertaken to compare values over time. A p-value $<0$ .05 was deemed significant. 


\section{Results}

Improved vitamin D and metabolic profile after 18 months of supplementation

The general characteristics of all T2DM subjects are presented in Table 1. Vitamin D deficiency was noted in all subjects. Despite supplementation, all subjects remained vitamin $D$ deficient by as much as $22 \%$ even after 18 months of therapy. None of the subjects reported changes in their oral hypoglycemic agent, insulin and statin dosage. Of the 120 subjects who enrolled, 92 subjects (34 males and 58 females) (23.3\% attrition rate) were able to complete the entirety of the 18 month supplementation. There was a significant improvement in the circulating levels of 25-hydroxyvitamin D from baseline to 6 months $(32.2 \pm 1.5$ vs. $57.7 \pm 1.4 \mathrm{nmol} / \mathrm{l})$ $(\mathrm{p}<0.001)$, and these levels remained unchanged over the course of the supplementation period. In parallel, a significant improvement in the lipid profile of subjects was observed as evidenced by a decrease in total cholesterol $(4.8 \pm 0.28 \mathrm{mmol} / \mathrm{l})$ as compared to baseline $(5.4 \pm 0.21 \mathrm{mmol} / \mathrm{l})(\mathrm{p}<0.001)$, as well as LDL-cholesterol
$(4.3 \pm 0.93 \mathrm{vs} .3 .7 \pm 1.0 \mathrm{mmol} / \mathrm{l})(\mathrm{p}=0.004)$ after 18 months. Worthy to note was the non-significant increase in HDLcholesterol across time points. Other metabolic parameters that changed significantly were an increase of serum calcium $(\mathrm{p}=0.003)$; insulin $(\mathrm{p}<0.001)$ and HOMA-IR $(\mathrm{p}<0.001)$, and HOMA- $\beta$ cell function $(\mathrm{p}=0.002)$. Of note was the significant decrease in serum albumin $(\mathrm{p}<0.001)$. The rest of the parameters (blood pressure, BMI, glucose, serum magnesium and phosphorus were similar.

\section{Gender differences in metabolic improvements after vitamin D supplementation}

We examined whether there were apparent differences in the improvement of metabolic profile in males vs. females (Table 2). In males, there was an increase in the circulating levels of 25-hydroxyvitamin $\mathrm{D}$ that was apparent on the 6 month evaluation (30.9 \pm 1.4 vs. $55.7 \pm 1.3 \mathrm{nmol} / \mathrm{l}, \mathrm{p}<0.001)$. A significant increase was also observed in serum calcium levels in men but not women $(p=0.03)$. The improvement in metabolic

Table 1 General characteristics of all T2DM subjects according to follow-up

\begin{tabular}{|c|c|c|c|c|c|}
\hline & Baseline & 6 Months & 12 Months & 18 Months & $P$ value \\
\hline $\bar{N}$ & 92 & & & & \\
\hline$M / F$ & $34 / 58$ & & & & \\
\hline DMT2 Duration (years) & $7.2 \pm 5.9$ & & & & \\
\hline Insulin (N\%) & 18 (19.6) & & & & \\
\hline Sulfonylurea (N\%) & $68(73.9)$ & & & & \\
\hline Statins (N\%) & $44(47.8)$ & & & & \\
\hline Diet (N\%) & $6(6.5)$ & & & & \\
\hline Age (years) & $53.9 \pm 10.2$ & & & & \\
\hline Systolic BP (mmHg) & $126.0 \pm 14.1$ & $125.3 \pm 17.2$ & $128.4 \pm 14.4$ & $126.1 \pm 8.1$ & 0.46 \\
\hline Diastolic BP (mmHg) & $79.6 \pm 7.3$ & $79.0 \pm 10.1$ & $79.6 \pm 9.5$ & $77.2 \pm 6.2$ & 0.27 \\
\hline $\mathrm{BMI}\left(\mathrm{kg} / \mathrm{m}^{2}\right)$ & $32.5 \pm 5.0$ & $32.6 \pm 4.9$ & $32.8 \pm 4.9$ & $33.2 \pm 5.2$ & 0.12 \\
\hline Glucose $(\mathrm{mmol} / \mathrm{l})$ & $10.7 \pm 3.8$ & $11.0 \pm 4.3$ & $11.7 \pm 4.1$ & $10.9 \pm 4.4$ & 0.21 \\
\hline T. Cholesterol (mmol/l) & $5.4 \pm 0.21$ & $5.2 \pm 0.25$ & $4.9 \pm 0.22^{*}$ & $4.8 \pm 0.28^{*}$ & $<0.001$ \\
\hline Triglycerides (mmol/l) & $1.9 \pm 0.33$ & $2.0 \pm 0.32$ & $1.9 \pm 0.26$ & $1.9 \pm 0.34$ & 0.15 \\
\hline HDL-Chol (mmol/l) & $1.0 \pm 0.35$ & $1.1 \pm 0.26$ & $1.12 \pm 0.27$ & $1.2 \pm 0.37$ & 0.38 \\
\hline LDL-Chol (mmol/l) & $4.3 \pm 0.93$ & $4.0 \pm 0.85$ & $3.7 \pm 1.1^{*}$ & $3.7 \pm 1.0^{*}$ & 0.004 \\
\hline Corr. Calcium (mmol/l) & $2.3 \pm 0.23$ & $2.4 \pm 0.17$ & $2.5 \pm 0.22$ & $2.56 \pm 0.14^{*}$ & 0.003 \\
\hline Albumin $(\mathrm{g} / \mathrm{L})$ & $43.5 \pm 6.5$ & $40.3 \pm 6.6$ & $40.0 \pm 4.0^{*}$ & $39.5 \pm 4.7^{*}$ & $<0.001$ \\
\hline Insulin (IU/ml) & $14.0 \pm 2.0$ & $18.9 \pm 2.3$ & $27.0 \pm 1.8^{*}$ & $24.5 \pm 2.1^{*}$ & $<0.001$ \\
\hline PTH (pmole/l) & $1.3 \pm 0.39$ & $0.96 \pm 0.24$ & $0.91 \pm 0.22^{*}$ & $0.92 \pm 0.23^{*}$ & 0.02 \\
\hline HOMA-IR & $6.2 \pm 1.0$ & $8.0 \pm 1.0$ & $11.9 \pm 1.0^{*}$ & $11.4 \pm 1.4^{*}$ & $<0.001$ \\
\hline HOMA $\beta$-cell function & $52.1 \pm 9.0$ & $72.5 \pm 15.3$ & $82.7 \pm 9.5^{*}$ & $96.5 \pm 15.3^{*}$ & 0.002 \\
\hline 25-(OH) D (nmol/l) & $32.2 \pm 1.5$ & $57.7 \pm 1.4^{*}$ & $48.1 \pm 1.4^{*} \#$ & $54.7 \pm 1.5^{*}$ & $<0.001$ \\
\hline Magnesium (mmol/l) & $0.69 \pm 0.11$ & $0.67 \pm 0.08$ & $0.66 \pm 0.05$ & $0.70 \pm 0.15$ & 0.65 \\
\hline Phosphorus (mmol/l) & $1.17 \pm 0.23$ & $1.17 \pm 0.23$ & $1.13 \pm 0.22$ & $1.11 \pm 0.23$ & 0.16 \\
\hline
\end{tabular}

Note: Data presented as mean $\pm \mathrm{SD}$; ${ }^{*}$ denotes significance compared to baseline; \# denotes significance compared to 6 months; P-value significant at $<0.05$. 
Table 2 General characteristics of male and female T2DM subjects according to follow-up

\begin{tabular}{|c|c|c|c|c|c|c|c|c|c|c|}
\hline & \multicolumn{5}{|c|}{ MALES } & \multicolumn{5}{|c|}{ FEMALES } \\
\hline & Baseline & 6 Months & 12 Months & 18 Months & P val & Baseline & 6 Months & 12 Months & 18 Months & $\mathrm{P}$ val \\
\hline N & 34 & & & & & 58 & & & & \\
\hline DMT2 Duration (years) & $7.3 \pm 6.5$ & & & & & $7.1 \pm 5.5$ & & & & \\
\hline Age (years) & $56.6 \pm 8.7$ & & & & & $51.2 \pm 10.6$ & & & & \\
\hline Systolic BP (mmHg) 1 & $127.0 \pm 15.2$ & $125.2 \pm 17.5$ & $131.7 \pm 16.2$ & $124.9 \pm 8.5$ & 0.05 & $127.3 \pm 13.4$ & $125.4 \pm 17.2$ & $126.3 \pm 12.9$ & $126.7 \pm 7.8$ & 0.90 \\
\hline Diastolic BP (mmHg) & $79.3 \pm 7.4$ & $80.4 \pm 10.1$ & $80.7 \pm 8.5$ & $76.2 \pm 5.1$ & 0.10 & $79.7 \pm 7.3$ & $78.0 \pm 10.1$ & $78.9 \pm 10.1$ & $77.9 \pm 7.1$ & 0.72 \\
\hline BMI $\left(\mathrm{kg} / \mathrm{m}^{2}\right)$ & $29.0 \pm 3.3$ & $29.2 \pm 3.7$ & $29.1 \pm 3.7$ & $29.7 \pm 4.3$ & 0.41 & $34.2 \pm 4.9$ & $34.4 \pm 4.6$ & $34.7 \pm 4.5$ & $3.4 .9 \pm 4.7$ & 0.30 \\
\hline Glucose $(\mathrm{mmol} / \mathrm{l})$ & $10.9 \pm 4.6$ & $10.8 \pm 3.8$ & $12.8 \pm 3.9$ & $11.3 \pm 5.2$ & 0.11 & $10.6 \pm 3.4$ & $11.2 \pm 4.6$ & $11.2 \pm 4.1$ & $10.8 \pm 3.9$ & 0.70 \\
\hline T Cholesterol (mmol/l) & $5.4 \pm 1.2$ & $5.5 \pm 1.6$ & $5.0 \pm 1.0$ & $4.9 \pm 1.1$ & 0.11 & $5.5 \pm 0.84$ & $5.3 \pm 1.0$ & $4.9 \pm 0.99^{*}$ & $4.9 \pm 1.2^{*}$ & $<0.001$ \\
\hline Triglycerides (mmol/l) & $1.8 \pm 0.31$ & $2.1 \pm 0.32$ & $2.0 \pm 0.29$ & $1.8 \pm 0.32$ & 0.25 & $1.9 \pm 0.35$ & $2.0 \pm 0.33$ & $1.7 \pm 0.25$ & $1.9 \pm 0.34$ & 0.14 \\
\hline HDL-Chol (mmol/l) & $1.4 \pm 0.29$ & $1.1 \pm 0.07$ & $1.1 \pm 0.11$ & $1.1 \pm 0.12$ & 0.10 & $1.0 \pm 0.12$ & $1.1 \pm 0.13$ & $1.1 \pm 0.13$ & $1.2 \pm 0.17$ & 0.16 \\
\hline LDL-Chol (mmol/l) & $4.2 \pm 1.5$ & $4.1 \pm 1.4$ & $4.0 \pm 1.9$ & $4.1 \pm 2.4$ & 0.68 & $4.4 \pm 0.80$ & $4.0 \pm 0.77$ & $3.6 \pm 0.90^{*}$ & $3.6 \pm 0.77^{*}$ & 0.004 \\
\hline Corr. Calcium (mmol/l) & $2.2 \pm 0.22$ & $2.4 \pm 0.19$ & $2.5 \pm 0.27^{*}$ & $2.5 \pm 0.10^{*}$ & 0.03 & $2.4 \pm 0.21$ & $2.4 \pm 0.16$ & $2.5 \pm 0.19$ & $2.5 \pm 0.17$ & 0.06 \\
\hline Albumin $(\mathrm{g} / \mathrm{L})$ & $47.0 \pm 7.9$ & $43.9 \pm 9.0$ & $42.3 \pm 3.0$ & $42.6 \pm 4.4$ & 0.11 & $41.6 \pm 4.5$ & $38.3 \pm 3.4^{*}$ & $39.4 \pm 3.9^{*}$ & $37.7 \pm 4.0^{*}$ & $<0.001$ \\
\hline Insulin (IU/ml) & $15.2 \pm 1.9$ & $18.9 \pm 2.2$ & $24.5 \pm 2.1$ & $21.5 \pm 2.1$ & 0.23 & $13.0 \pm 2.1$ & $19.0 \pm 2.4$ & $28.5 \pm 1.6^{*}$ & $22.0 \pm 2.2^{*}$ & 0.001 \\
\hline PTH (pmole/l) & $1.1 \pm 0.32$ & $0.88 \pm 0.20$ & $0.89 \pm 0.23$ & $0.91 \pm 0.24$ & 0.06 & $1.4 \pm 0.44$ & $0.99 \pm 0.34$ & $0.97 \pm 0.35$ & $0.98 \pm 0.32$ & 0.09 \\
\hline HOMA-IR & $6.8 \pm 0.86$ & $8.2 \pm 0.96$ & $11.1 \pm 0.99$ & $12.2 \pm 1.1$ & 0.32 & $5.8 \pm 1.0$ & $8.2 \pm 0.99$ & $12.4 \pm 0.97^{*}$ & $=11.2 \pm 1.3^{*}$ & 0.01 \\
\hline HOMA $\beta$ function (\%) & $52.0 \pm 12.9$ & $69.5 \pm 10.7$ & $66.1 \pm 8.7$ & $85.9 \pm 15.3$ & 0.12 & $50.6 \pm 7.8$ & $74.4 \pm 18.1$ & $91.6 \pm 9.8^{*}$ & $86.3 \pm 15.2^{*}$ & 0.004 \\
\hline $25-(\mathrm{OH}) \mathrm{D}(\mathrm{nmol} / \mathrm{l})$ & $30.9 \pm 1.4$ & $55.7 \pm 1.3^{*}$ & $50.6 \pm 1.3^{*}$ & $55.7 \pm 1.2^{*}$ & $<0.001$ & $33.7 \pm 1.6$ & $59.7 \pm 1.4^{*}$ & $46.7 \pm 1.5^{*}$ & $54.9 \pm 1.5^{*}$ & $<0.001$ \\
\hline Magnesium (mmol/l) & $0.71 \pm 0.19$ & $0.7 \pm 0.07$ & $0.70 \pm 0.04$ & $0.71 \pm 0.05$ & 0.90 & $0.69 \pm 0.08$ & $0.65 \pm 0.08$ & $0.65 \pm 0.04$ & $0.70 \pm 0.19$ & 0.73 \\
\hline Phosphorus (mmol/l) & $1.20 \pm 0.25$ & $1.15 \pm 0.21$ & $1.05 \pm 0.22$ & $1.04 \pm 0.19^{*}$ & 0.009 & $1.15 \pm 0.22$ & $1.20 \pm 0.21$ & $1.17 \pm 0.22$ & $1.16 \pm 0.25$ & 0.52 \\
\hline
\end{tabular}

Note: Data presented as mean \pm SD; * denotes significance compared to baseline; \# denotes significance compared to 6 months; P-value significant at $<0.05$.

profile was more apparent in females, and showing improved levels in total and LDL-cholesterol $(\mathrm{p}<0.001$ and 0.004 , respectively), albumin $(\mathrm{p}<0.001)$, insulin $(\mathrm{p}<0.001)$, HOMA-IR $(\mathrm{p}<0.01)$ and HOMA- $\beta$ cell function ( $\mathrm{p}<0.004)$, as well as 25-hydroxyvitamin D $(\mathrm{p}<0.001)$. Figure 1 shows the increasing pattern of HOMA- $\beta$ secretion improvement over time despite a sustained, almost significant increase in vitamin D levels beyond 6 months.

\section{Discussion}

The findings of this study indicate that the metabolic profile of T2DM subjects, particularly females, is significantly improved over a period of 18 months after the

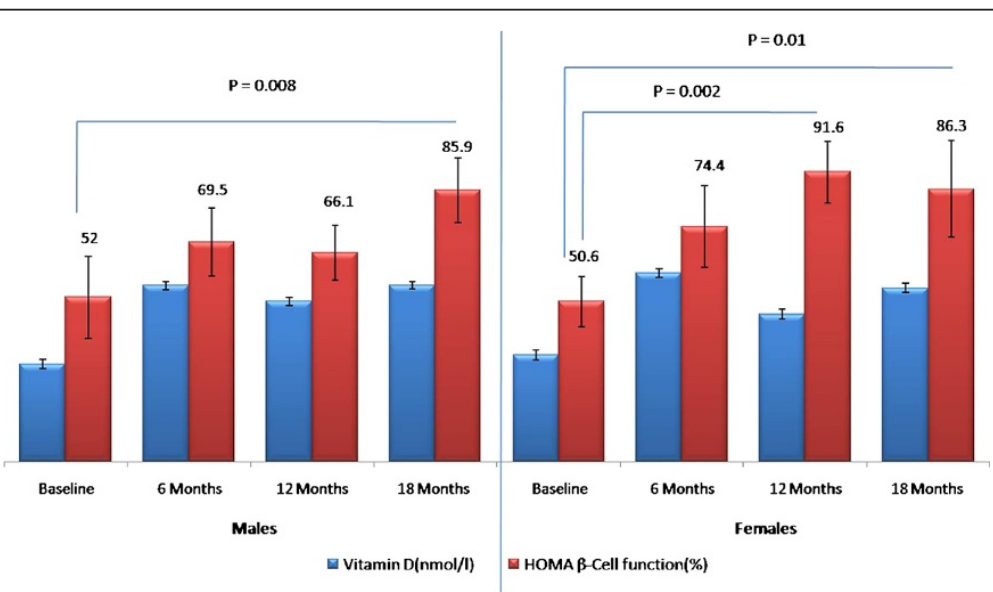

Figure 1 HOMA- $\beta$ cell function (\%) levels versus vitamin $D(\mathrm{nmol} / \mathrm{L})$ in male and female Saudi T2DM subjects who were on daily vitamin D3 (2000 IU) supplementation for 18 months in successive follow-up visits; significance at $\mathrm{P}<0.05$. 
onset of vitamin D3 supplementation, suggesting that vitamin $\mathrm{D}$ correction is a promising cardio-protective intervention in vitamin D-deficient populations. The gender effect can be attributed indirectly to either differences in hormone secretion and/or target tissue effects and body fat distribution, both of which can contribute to degrees of insulin resistance, or sample size effect. The current study adds to an increasing body of evidence that vitamin D supplementation is most beneficial not only to those who are at risk for osteoporosis and other bone-related diseases, but also to those who are deficient and have other extra skeletal chronic diseases, such as diabetes T2DM and cardiovascular disease. The available evidence, however, has been quite mixed. In a recent study, Eftekhari and colleagues were not able to elicit the same improved metabolic profile in an Iranian T2DM population, which was probably due to a shorter duration of supplementation (12 weeks) [21]. Other studies also found no improvement of insulin sensitivity after a high dose vitamin D intervention. This was probably partly due to the supplementation itself and/or because the subjects were apparently healthy $[22,23]$. Increased insulin resistance post supplementation was observed in a cohort of middle-aged adults, and increased insulin sensitivity in first time GDM patients $[24,25]$. In the present study, the apparent health benefits were observed after 6 months of supplementation, aside from the expected increase in circulating vitamin $D$ levels, suggesting that sustained and prolonged supplementation might be necessary to achieve desirable metabolic effects.

Several mechanisms explain how vitamin D can theoretically improve metabolic functions. One mechanism may involve direct promotion of large HDL particle formation, via elevations in serum apolipoprotein A1 (ApoA1) concentrations, a process that increases reverse cholesterol transport [26]. Furthermore, the improved lipid profile of the DMT2 subjects can also be attributed to lipid-lowering drugs, which were administered in almost half of the study population. Statins (rosuvastatin) were shown to increase levels of 25-hydroxyvitamin D and 1, 25 dihydroxyvitamin $\mathrm{D}$ in a cohort of hyperlipidemic patients [27]. Nevertheless, there is enough evidence to support that vitamin D supplementation can independently improve cardiovascular health secondary to its significant associations with cardiometabolic risk factors in both human and animal models, including blood pressure, insulin resistance and aortic media fragmentation, respectively [28-30]. The increase in serum calcium was expected, secondary to increased vitamin D levels. This in turn results in a parallel increase in localized calcium influx in pancreatic $\beta$ cells that stimulate islet insulin secretion [31-33]. Lastly, the inverse association to free albumin was also expected, as it is one of the proteins (vitamin $\mathrm{D}$ binding protein being the other one) that transport 25(OH)D in the blood [34].

Several caveats should be mentioned. First, the lack of a placebo-control group, second that the study included only patients with T2DM, and third, the difficulty in the verification of quality of life issues. Findings therefore are limited to patients with T2DM, since variations in metabolic changes differ not only by gender but also by the presence of the disease itself [35]. The increase in both insulin resistance and sensitivity should be interpreted with caution since these were computed indirectly rather than directly. Nevertheless, several hard outcomes were measured overtime, while HOMA- $\beta$ function would be difficult to elicit in a control group. The improved HOMA- $\beta$ function specifically in females can be also explained by several confounders that were not accounted for, such as the type of anti-diabetic drugs taken, compliance of the patients and duration of diabetes. Metformin for instance, does not confer changes in vitamin D status, while thiazolidinediones affect vitamin $\mathrm{D}$ by selective agonism of peroxisome proliferator activated receptors gamma (PPAR- $\gamma$ ), which are present in muscle, liver and adipose tissue [36].

In summary, the present interventional study performed in an Arab population suggests that daily 2000 IU vitamin D3 supplementation in a vitamin D deficient T2DM population is associated with measurable cardioprotective indices. Supplementation to achieve higher levels of vitamin $\mathrm{D}$ remains a promising adjuvant therapy for T2DM patients. Further studies are needed, with the inclusion of a placebo group, to validate the present findings.

\section{Competing interests}

The authors have no conflict of interest to disclose related to this study.

\section{Acknowledgements}

We thank the Prince Mutaib Chair for Biomarkers of Osteoporosis for the technical support. We also thank Benjamin Vinodson and Saim UI Haq for the statistical analysis of the data.

\section{Funding}

The authors are grateful to King Abdulaziz City of Science and Technology (KACST Grant no: AT-29-38), Riyadh, KSA for funding the study.

\section{Author details}

${ }^{1}$ Biomarkers Research Program, Biochemistry Department, College of Science, King Saud University, PO Box, 2455, Riyadh 11451, Kingdom of Saudi Arabia. ${ }^{2}$ Center of Excellence in Biotechnology Research Center, King Saud University, Riyadh 11451, Kingdom of Saudi Arabia. ${ }^{3}$ Prince Mutaib Chair for Biomarkers of Osteoporosis, King Saud University, Riyadh 11451, Kingdom of Saudi Arabia. ${ }^{4}$ Clinical Pharmacy Department, College of Pharmacy, King Saud University, Riyadh 11451, Kingdom of Saudi Arabia. ${ }^{5}$ College of Applied Medical Sciences, King Saud University, Riyadh 11451, Kingdom of Saudi Arabia. ${ }^{6}$ King Abdulaziz University Hospital, King Saud University, Riyadh 11451, Kingdom of Saudi Arabia. ${ }^{7}$ College of Medicine, King Saud University for Health Sciences, Riyadh 11426, Kingdom of Saudi Arabia. ${ }^{8} \mathrm{Clinical}$ Sciences Research Institute, Diabetes and Metabolism Unit, Coventry CV47AL, UK. ${ }^{9}$ First Department of Pediatrics, Athens University Medical School, Athens 11527, Greece. 


\section{Authors' contributions}

NMA and KMA conceived the study. AA, EE and OM recruited subjects and collected data. MSA and YA recruited subjects analyzed samples. SS performed data analysis and wrote the manuscript. SK and GC reviewed/ edited the final version of the manuscript. All authors approved the final manuscript.

Received: 2 June 2012 Accepted: 18 July 2012

Published: 18 July 2012

\section{References}

1. Forouhi NG, Luan J, Cooper A, Boucher BJ, Wareham NJ: Baseline serum 25-hydroxy vitamin $d$ is predictive of future glycemic status and insulin resistance: the medical research council Ely prospective study 1990-2000. Diabetes 2008, 57:2619-2625.

2. Forouhi NG, Ye Z, Rickard AP, Khaw KT, Luben R, Langenberg C, Wareham NJ: Circulating 25-hydroxyvitamin D concentration and the risk of type 2 diabetes: results from the European Prospective Investigation into Cancer (EPIC)-Norfolk cohort and updated meta-analysis of prospective studies. Diabetologia 2012, 55:2173-2182

3. Akin F, Ayça B, Köse N, Duran M, Sar M, Uysal OK, Karakukcu C, Arinc $H_{\text {, }}$ Covic A, Goldsmith D, Okçün B, Kanbay M: Serum vitamin D levels are independently associated with severity of coronary artery disease. J Investig Med 2012, [Epub ahead of print].

4. Mathieu C, Badenhoop K: Vitamin D and type 1 diabetes mellitus: state of the art. Trends Endocrinol Metab 2005, 16:261-266.

5. Mattila C, Knekt P, Männistö S, Rissanen H, Laaksonen MA, Montonen J, Reunanen A: Serum 25-hydroxyvitamin D concentration and subsequent risk of type 2 diabetes. Diabetes Care 2007, 30:2569-2570.

6. Di Cesar DJ, Ploutz-Snyder R, Weinstock RS, Moses AM: Vitamin D deficiency is more common in type 2 than in type 1 diabetes. Diabetes Care 2006, 29:174.

7. Grimnes G, Emaus N, Joakimsen RM, Figenschau Y, Jenssen T, Niolstad I, Schirmer $\mathrm{H}$, Jorde R: Baseline serum 25-hydroxyvitamin D concentrations in the Tromso Study 1994-1995 and risk of developing type 2 diabetes mellitus during 11 years of follow-up. Diabet Med 2011, 27:1107-1115.

8. Deleskog A, Hilding A, Brismark K, Hamsten A, Efendic S, Ostenson CG: Low serum 25-hydroxyvitamin D levels predict progression to type 2 diabetes in individuals with prediabetes but not with normal glucose tolerance. Diabetologia 2012, 55:1668-1678.

9. Harris SS: Does vitamin D deficiency contribute to increased rates of cardiovascular disease and type 2 diabetes in African Americans. Am J Clin Nutr 2011, 93:1175S-1178S

10. Boucher BJ: Hypovitaminosis D and risk of type 2 diabetes in British South Asians. Diabet Med 2006, 23:336.

11. Nsiah-Kumi PA, Erickson JM, Beals JL, Ogle EA, Whiting M, Brushbreaker C, Borgeson CD, Qiu F, Yu F, Larsen JL: Vitamin D insufficiency is associated with diabetes risk in Native American children. Clin Pediatr (Phila) 2012 51:146-153.

12. Maalouf G, Gannage-Yared MH, Ezzedine J, Larijani B, Badawi S, Rached A, Zakroui L, Masri B, Azar E, Saba E, Nammari R, Adib G, Abou Samra H, Alrawi Z, Salman S, El Muntasser K, Tarseen R, El Kharousi W, Al-Lamki M, Alothman AN, Almarzook N, El Dessouki M, Sulaimani R, Saleh J, Suhaili AR, Khan A, Delmas P, Seeman E: Middle East and North Africa consensus on osteoporosis. Journal of Muskuloskeletal and Neuronal Interaction 2007, 7:131-143.

13. Al-Daghri NM, Al-Attas OS, Alokail MS, Alkharfy KM, El-Kholie E, Yousef M, AlOthman A, Al-Saleh Y, Sabico S, Kumar S, Chrousos GP: Increased vitamin D supplementation recommended during summer season in the gulf region: a counterintuitive seasonal effect in vitamin $D$ levels in adult, overweight and obese Middle Eastern residents. Clin Endocrinol (Oxf) 2012, 76:346-350.

14. Rouzi AA, Al-Sibiani SA, Al-Senani NS, Radaddi RM, Ardawi MS: Independent predictors of osteoporosis-related fractures among healthy Saudi postmenopausal women: the CEOR study. Bone 2012, 50:713-722.

15. Ardawi MS, Sibiany MM, Bakhsh TM, Qari MH, Maimani AA: High prevalence of vitamin D deficiency among healthy Saudi Arabian men: relationship to bone mineral density, parathyroid hormone, bone turnover markers, and lifestyle factors. Osteoporos Int 2012, 23:675-686.

16. Al-Daghri NM, Al-Attas OS, Alokail MS, Alkharfy KM, Yousef M, Nadhrah HM, Al-Othman A, Al-Saleh Y, Sabico S, Chrousos GP: Hypovitaminosis D and cardiometabolic risk factors among non-obese youth. Cent Eur J Med 2010, 5:752-757

17. Al-Daghri NM, Al-Attas OS, Al-Okail MS, Alkharfy KM, Al-Yousef MA, Nadhrah $\mathrm{MH}$, Sabico SB, Chrousos GP: Severe hypovitaminosis D is widespread and more common in non-diabetics than diabetics in Saudi adults. Saudi Med J 2010, 31:775-780.

18. Al-Daghri NM, Al-Attas OS, Alokail MS, Alkharfy KM, Yousef M, Sabico SL, Chrousos GP: Diabetes mellitus type 2 and other chronic non$\mathrm{cmm}$ unicable diseases in the central region, Saudi Arabia (Riyadh cohort 2): a decade of an epidemic. BMC Medicine 2011, 9:76.

19. Al-Daghri NM, Alkharfy KM, Al-Saleh Y, Al-Attas OS, Alokail MS, Al-Othman A, Moharram O, El-Kholie E, Sabico S, Kumar S, Chrousos GP: Modest reversal of metabolic syndrome manifestations with vitamin D status correction: a 12-month prospective study. Metabolism 2012, 61:661-666.

20. Wallace TM, Levy JC, Matthews DR: Use and abuse of HOMA modelling Diabetes Care 2004, 27:1487-1495.

21. Eftekhari MH, Akbarzadeh M, Dabbaghmanesh MH, Hasanzadeh J: Impact of treatment with oral calcitriol on glucose indices in type 2 diabetes mellitus patients. Asia Pac J Clin Nutr 2011, 20:521-526.

22. Grimnes G, Figenschau Y, Almas B, Jorde R: Vitamin D, insulin secretion, sensitivity, and lipids: results from a case-control study and a randomized controlled trial using hyperglycaemic clamp technique. Diabetes 2011, 60:2748-2757.

23. Tai K, Need AG, Horowitz M, Chapman IM: Glucose tolerance and vitamin D: effects of treating vitamin D deficiency. Nutrition 2008, 24:950-956.

24. Kaviani M, Abdollahian M, Almasi V, Amini M, Yamini AA: Effects of vitamin $D$ on insulin resistance in nursing home residents: an interventional study. Endokrynol Pol 2012, 63:191-195.

25. Mozaffari-Khosravi H, Hosseinzadeh-Shamsi-Anar M, Salami MA, Hadinedoushan $\mathrm{H}$, Mozayan MR: Effects of a single post-partum injection of a high dose of vitamin D on glucose tolerance and insulin resistance in mothers with first-time gestational diabetes mellitus. Diabet Med 2012, 29:36-42.

26. Kazlauskaite R, Powell LH, Mandapakala C, Cursio JF, Avery EF, Calvin J: Vitamin $D$ is associated with atheroprotective high density lipoprotein profile in postmenopausal women. J Clin Lipidol 2010, 4:113-119.

27. Yavuz B, Ertugrul DT, Cil H, Ata N, Akin KO, Yalcin AA, Kucukazman M, Dal K, Hokkaomeroglu MS, Yavuz BB, Tutal E: Increased levels of 25hydroxyvitamin D and1,25-dihydroxyvitamin D after rosuvastatin treatment: a novel pleiotropic effect of statins? Cardiovasc Drugs Ther 2009, 23:295-299.

28. Vacek JL, Vanga SR, Good M, Lai SM, Lakkireddy D, Howard PA: Vitamin D deficiency nd supplementation and relation to cardiovascular health. Am J Cardiol 2012, 109:359-363.

29. Salum E, Kampus P, Zilmer M, Eha J, Butlin M, Avolio AP, Põdramägi T, Arend A, Marina Aunapuu M, Kals J: Effect of vitamin D on aortic remodeling in streptozotocin-induced diabetes. Cardiovasc Diabeto/ 2012, 11:58.

30. Gagnon C, Lu ZX, Magliano DJ, Dunstan DW, Shaw JE, Zimmet PZ, Sikaris K, Ebeling PR, Daly RM: Low serum 25-hydroxyvitamin D is associated with increased risk of the development of the metabolic syndrome at five years: results from a national, population-based prospective study (The Australian diabetes, obesity and lifestyle study. AusDiab. J Clin Endocrinol Metab 2012, [Epub ahead of print].

31. Satin LS: Localized calcium influx in pancreatic beta-cells: its significance for $\mathrm{Ca}^{2+}$-dependent insulin secretion from the islets of Langerhans. Endocrine 2000, 13:251-262.

32. Mears $\mathrm{D}$ : Regulation of insulin secretion in islets of Langerhans by $\mathrm{Ca}(2+)$ channels. J Membr Biol 2004, 200:57-66.

33. J Jing $X$, Li DQ, Olofsson CS, Salehi A, Surve W, Caballero J, Ivarsson R, Lundquist I, Pereverzev A, Schneider T, Rorsman P, Renstrom E: CaV2.3 calcium channels control second-phase insulin release. J Clin Invest 2005 115:146-154.

34. Bickle DD, Gee E, Halloran B, Kowalski MA, Ryzen E, Haddad JG: Assessment of the free fraction of 25 -hydroxyvitamin $D$ in serum and its regulation by albumin and the vitamin D-binding protein. J Clin Endocrinol Metab 1986, 63:954-959.

35. Håglin L, Bäckman L, Törnkvist B: A structural equation model for assessment of links between changes in serum triglycerides, -urate, andglucose and changes in serum calcium, -magnesium and -phosphate in 
type 2 diabetes and non-diabetes metabolism. Cardiovasc Diabetol 2011, 10:116.

36. Ogata T, Miyauchi T, Sakai S, Irukiyama-Tomobe Y, Goto K, Yamaguchi I: Stimulation of peroxisome-proliferator-activated receptor alpha (PPAR alpha) attenuates cardiac fibrosis and endothelin-1 production in pressure-overloaded rat hearts. Clin Sci (Lond) 2002, 103:284S-288S.

doi:10.1186/1475-2840-11-85

Cite this article as: Al-Daghri et al: Vitamin D supplementation as an adjuvant therapy for patients with T2DM: an 18-month prospective interventional study. Cardiovascular Diabetology 2012 11:85.

\section{Submit your next manuscript to BioMed Central and take full advantage of:}

- Convenient online submission

- Thorough peer review

- No space constraints or color figure charges

- Immediate publication on acceptance

- Inclusion in PubMed, CAS, Scopus and Google Scholar

- Research which is freely available for redistribution 